\title{
In Vitro Anticancer Effects of All-trans Retinoic Acid in Combination with Dacarbazine against CD117+ ${ }^{+}$Melanoma Cells
}

\author{
Authors \\ Bahareh Mohammadi Jobani, Elham Mohebi, Nowruz Najafzadeh(D)
}

\author{
Affiliation \\ Research Laboratory for Embryology and Stem Cells, \\ Department of Anatomical Sciences, School of Medicine, \\ Ardabil University of Medical Sciences, Ardabil, Iran \\ Key words \\ cancer stem cells, A375 melanoma cell line, CD117+ \\ all-trans retinoic acid \\ received 14.06 .2020 \\ accepted 10.08.2020 \\ published online $\quad 06.10 .2020$

\section{Bibliography} \\ Drug Res 2020; 70: 563-569 \\ DOI 10.1055/a-1240-0072 \\ ISSN 2194-9379 \\ (C) 2020. Thieme. All rights reserved. \\ Georg Thieme Verlag KG, Rüdigerstraße 14, \\ 70469 Stuttgart, Germany

\section{Correspondence} \\ Nowruz Najafzadeh, PhD \\ Associate Professor, Research Laboratory for Embryology \\ and Stem Cells \\ Department of Anatomical Sciences \\ Ardabil University of Medical Sciences \\ PO Box, 5618985991 Ardabil \\ Iran \\ nowruz30@gmail.com
}

\begin{abstract}
Background Malignant melanoma is a common form of skin cancer that contains different cell types recognized by various cell surface markers. Dacarbazine-based combination chemotherapy is frequently used for the treatment of melanoma. Despite its potent anticancer properties, resistance to dacarbazine develops in malignant melanoma. Here, we aim to improve response to dacarbazine therapy by pretreatment with all-trans retinoic acid (ATRA) in CD117 ${ }^{+}$melanoma cells.

Methods The $\mathrm{CD} 117^{+}$melanoma cells were sorted from A375 malignant melanoma cell line using magnetic-activated cell sorting (MACS). The cell viability was examined by cell proliferation assay (MTT). Apoptosis was determined by acridine orange/ ethidium bromide staining. Indeed, we performed flow cytometry to evaluate the cell cycle arrest.

Results Here, the $\mathrm{CD} 117^{+}$melanoma cells were incubated with various concentrations of ATRA, dacarbazine, and their combination to determine $I C_{50}$ values. We found that $20 \mu \mathrm{M}$ ATRA treatment followed by dacarbazine was found to be more effective than dacarbazine alone. There was an indication that the combination of ATRA with dacarbazine (ATRA/dacarbazine) caused more apoptosis and necrosis in the melanoma cells $(P<0.05)$. Furthermore, ATRA/dacarbazine treatment inhibited the cell at the G0/G1 phase, while dacarbazine alone inhibited the cells at $S$ phase.

Conclusion Collectively, combined treatment with ATRA and dacarbazine induced more apoptosis and enhanced the cell cycle arrest of CD117+ melanoma cells. These results suggested that ATRA increased the sensitivity of melanoma cells to the effect of dacarbazine.
\end{abstract}

\section{Introduction}

Human malignant melanoma is a highly metastatic type of skin cancer. Melanoma is markedly resistant to chemotherapy. The mortality rate is high in melanoma [1]. Unfortunately, the prevalence of melanoma has been rising annually [2], but the survival rate of patients diagnosed with melanoma has improved considerably over the past decades [3]. Melanoma is curable at early stages before the cells invade the lower layers of skin. Complete surgical excision used for the treatment of primary lesions of melanoma. The success of the surgery is minimal in malignant metastatic melanoma. Unfortunately, melanoma can remain asymptomatic for a longtime and may invade multiple organs such as lung, bone, brain, and liver [4]. Dacarbazine, temozolomide, and ipilimumab approved for the treatment of metastatic melanoma. Unfortunately, remission may occur after chemotherapy [5]. Indeed, melanoma is resistant to other drugs such as doxorubicin, etoposide, IL-2, and IFN- $\alpha$ $[4,6]$. Therefore, melanoma cells may acquire chemoresistance during or after chemotherapy. P-glycoprotein and multidrug resistant protein MDR1 are upregulated in melanoma. Indeed, downregulation of topoisomerase II and hyperactivation of DNA repair are the possible mechanisms of chemoresistance in melanoma cells [7].

CD117 (c-KIT), as a member of the tyrosine kinase family, interacts with stem cell factors (SCF). Activation of CD117 increases pro- 
liferation, cell survival, migration, and differentiation. The c-kit gain of function mutations has been linked to several cancers such as melanoma, gastrointestinal stromal tumor, acute myeloid leukemia, and testicular cancer [8]. Also, CD117 is expressed in prostate stem cells [9] and hematopoietic stem cells [10]. Previous studies suggested that CD117 plays a critical role in cancer stem cells (CSCs) of non-small lung cancer and ovarian tumor [11]. It may play a role in the progression and metastasis of melanoma. Garcia et al. showed that CD117 was positive in most metastatic melanoma samples; they conclude that CD117 immunoreactivity may be useful in the differential diagnosis of malignant melanoma from clear cell sarcoma [12]. Indeed, it has been shown that CD117 expression increases in metastatic sites of melanoma. Awareness of the expression of CD117 markers in metastatic melanomas may be of importance to identifying novel therapeutic interventions to target $\mathrm{CD} 117^{+}$metastatic melanoma cells.

ATRA has been suggested to promote apoptosis in melanoma cell lines through cell cycle arrest and dysfunction of mitochondria by binding to retinoic acid receptors (RARs) and retinoic acid $\times$ receptors (RXR) [13]. Moreover, Yin et al. showed that ATRA inhibits murine melanoma cell growth by promoting the differentiation and the cytotoxic function of effector $C D 8^{+} \mathrm{T}$ cells [14]. Although the mechanism of ATRA on regulating apoptosis of melanoma cells is not fully elucidated, it has been suggested that induction of differentiation and apoptosis by retinoic acids may contribute to the treatment of cancers.

Dacarbazine (DTIC) damages DNA and causes cell death. Unfortunately, the response rate for dacarbazine monotherapy is low in malignant melanoma. Dacarbazine can cause common side effects, such as anemia, neutropenia, vomiting, and nausea [15]. This limitation may be overcome by using a combination of lower dosages of chemotherapy agents. Studies have shown that ATRA combination with chemotherapy agents can inhibit the proliferation of gastrointestinal cancers [16], ovarian adenocarcinoma, and squamous head and neck cancers [17].

The importance of CD117 in normal melanocyte and melanoma cell development is well established. The elimination of CD117 cells in malignant melanoma may be an effective therapy. Therefore, we hypothesized that the subtoxic concentration of ATRA might improve the efficacy of dacarbazine in the CD117 ${ }^{+}$melanoma cells.

\section{Material and Methods}

\section{Drugs and reagents}

MTT (3-(4, 5-dimethylthiazol-2-yl)-2, 5-diphenyltetrazolium bromide, M2128), dacarbazine (D2390), and ATRA (R2625) were purchased from Sigma-Aldrich (St. Louis, MO, USA). ATRA dissolved in ethanol $96 \%$ at $0.01 \mathrm{M}$ and kept frozen $(-80)$ as a stock solution. Dacarbazine dissolved in phosphate saline buffer and diluted in RPMI 1640.

\section{Cell line and cell culture}

The human melanoma, A375 cell line, was obtained from the National Cell Bank of Iran (NCBI, Pasteur Institute of Iran, Tehran). The cells were cultured in RPMI 1640 (Gibco, UK) medium supplement- ed with $15 \%$ fetal bovine serum (FBS; Cat. Number 10270-106, Gibco, UK) and $1 \%$ Penicillin/streptomycin (Gibco: 15140-122). The cells were incubated at $37^{\circ} \mathrm{C}$ under a humidified atmosphere.

\section{Separation of CD117 ${ }^{+}$cells by MACS}

The $\mathrm{CD} 117^{+}$cells were isolated from the A375 melanoma cell line as previously described $[18,20]$. The melanoma cells were harvested, prepared into single-cell suspension, and counted. For the selection of CD117 single-positive cells, the cells were stained with a PE-conjugated CD117 antibody (Miltenyi Biotec, 130-099-672) and incubated for $15 \mathrm{~min}$ at room temperature. The cells rinsed with wash buffer and incubated with anti-PE Microbeads (Miltenyi Biotec, $130-048-801$ ) for $20 \mathrm{~min}$ at $4-8^{\circ} \mathrm{C}$. The cells passed through the MS column. Finally, the retained cells eluted with $500 \mu$ lof the cold autoMACS solution. Magnetic separation was performed twice to obtain a higher percentage of $\mathrm{CD} 117^{+}$cell populations.

\section{MTT assay}

Briefly, for evaluation of cytotoxicity of the drugs, the CD117 ${ }^{+}$cells were cultured in 96 well plates. The $\mathrm{CD} 117^{+}$cells were treated with various concentrations of ATRA, dacarbazine, and ATRA/dacarbazine. The groups include: (i) untreated control (ii) ATRA (4-64 $\mu \mathrm{M})$ (iii) dacarbazine $(0,800,1000,1200,1400 \mu \mathrm{g} / \mathrm{ml})$ and (iv) ATRA/

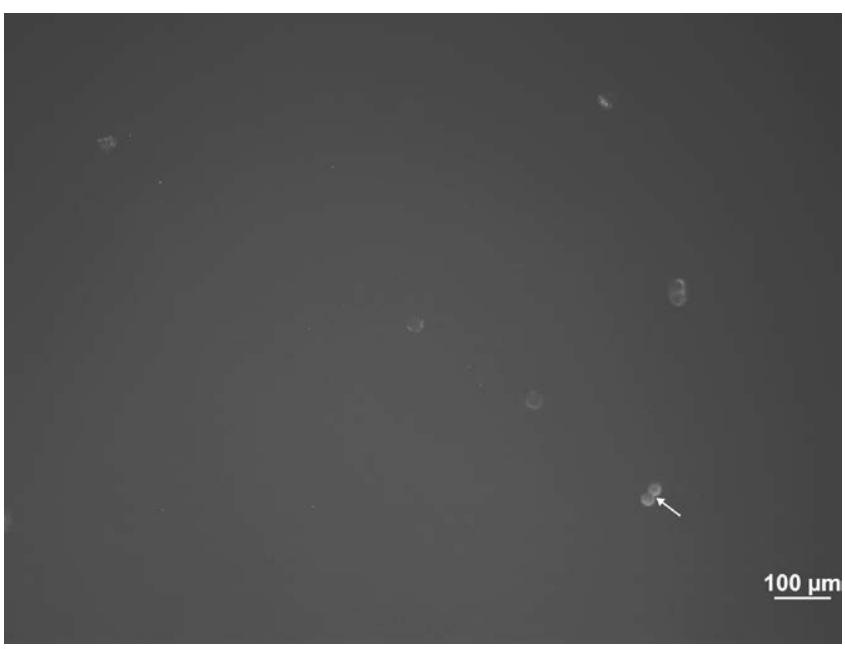

- Fig. 1 Isolation of $\mathrm{CD} 117^{+}$cells from A375 melanoma cell line using a magnetically activated cell sorting method. The cells were identified by fluorescence microscopy. White arrows show CD117 positive cell.

- Table 1 The $\mathrm{CD} 117^{+}$melanoma cells were treated with different concentrations of ATRA, dacarbazine, and ATRA/dacarbazine. IC50 values of the drugs against $\mathrm{CD} 117^{+}$melanoma cells were calculated using Sigmaplot $(n=3$, Mean \pm STDEV $)$.

\begin{tabular}{|l|l|}
\hline & CD117 $^{+}$ \\
\hline ATRA & $8.09 \pm 1.72 \mu \mathrm{M}$ \\
\hline dacarbazine & $1583.09 \pm 133.84 \mu \mathrm{g} / \mathrm{ml}$ \\
\hline ATRA $(\mathbf{5} \boldsymbol{\mu M}) /$ dacarbazine & $1610.97 \pm 210.89 \mu \mathrm{g} / \mathrm{ml}$ \\
\hline ATRA $(\mathbf{1 0} \mu \mathrm{M}) /$ dacarbazine & $1583.34 \pm 45.26 \mu \mathrm{g} / \mathrm{ml}$ \\
\hline ATRA $(\mathbf{2 0} \mu \mathrm{M}) /$ dacarbazine & $914.21 \pm 51.3^{*} \mu \mathrm{g} / \mathrm{ml}$ \\
\hline${ }^{*} P<0.05$ compared to dacarbazine treated cells. \\
\hline
\end{tabular}


dacarbazine ; 4 h pretreatment with 5, 10 and $20 \mu \mathrm{M}$ concentrations of ATRA, then the cells incubated in various concentration of dacarbazine $(0,800,1000,1200,1400 \mu \mathrm{g} / \mathrm{ml})$ for $48 \mathrm{~h}$. Following incubation, $180 \mu \mathrm{l}$ serum-free medium and $20 \mu \mathrm{l}$ MTT solution ( $5 \mathrm{mg} / \mathrm{ml}$, Sigma, M2128) were added and incubated at $37^{\circ} \mathrm{C}$ for $4 \mathrm{~h}$. The supernatant was removed and replaced by $200 \mu \mathrm{l}$ of DMSO (Scharlau Chemie, Barcelona, Spain) to dissolve formazan crystals for 5 min at $37^{\circ} \mathrm{C}$. Finally, the survival fraction of the cells was measured at $480 \mathrm{~nm}$ by using an ELISA reader (Bio Tek). The inhibitory effect of the drugs at each concentration was expressed as a percentage of the control group (mean OD of treated cells/mean OD of control) $\times 100$.

\section{Acridine Orange/Ethidium Bromide (AO/EB) staining}

The $\mathrm{CD} 117^{+}$melanoma cells were seeded in 12 well plates. We evaluated the cell proliferation following treatment with dacarbazine $(800-1400 \mu \mathrm{g} / \mathrm{ml})$, ATRA $(10 \mu \mathrm{M}) /$ dacarbazine $(800-1400 \mu \mathrm{g} / \mathrm{ml})$, and ATRA $(20 \mu \mathrm{M}) /$ dacarbazine $(800-1400 \mu \mathrm{g} / \mathrm{ml})$. Following incubation, $100 \mu \mathrm{l}$ AO/EB staining solution $(100 \mu \mathrm{g} / \mathrm{ml}$ AO and $100 \mu \mathrm{g} / \mathrm{ml}$
EB) was added to each well. The morphological changes were evaluated using fluorescent microscopy. Apoptotic cells revealed nuclei containing condensed and fragmented chromatin. Necrotic cells were stained with $\mathrm{EB}$ and detected by uniformly orange cell nuclei. Finally, the cells were analyzed by a fluorescence microscope (DP71, Olympus).

\section{Cell cycle assay}

Briefly, after the treatment ((i) control, (ii) ATRA, (iii) dacarbazine, and (iv) ATRA/dacarbazine), the CD117 ${ }^{+}$melanoma cells were trypsinized and suspended in PBS and fixed with cold $70 \%$ ethanol. Then, the fixed cells washed with PBS and stained with 4, 6-diamidino-2-phenylindole dihydrochloride solution (DAPI, $1 \mu \mathrm{g} / \mathrm{ml}, 1 \%$ Triton X-100 in PBS) for $30 \mathrm{~min}$ at $37^{\circ} \mathrm{C}$ in a dark room. The stained cells were passed through a $30 \mu \mathrm{m}$ nylon mesh filter. The distribution of cells in cell cycle phases was assessed by flow cytometry (Partec Cyflow space, Germany).
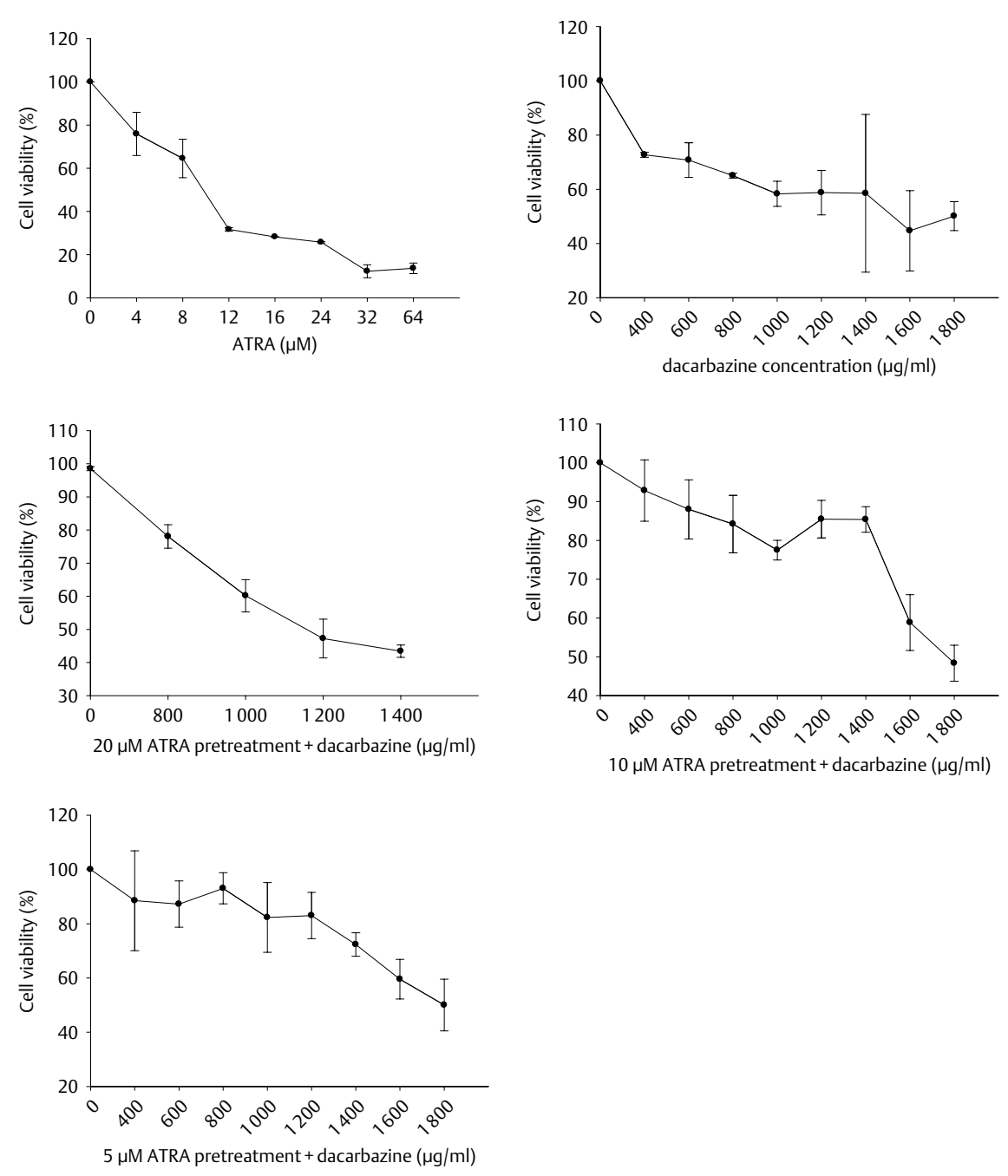

-Fig. 2 The combination of ATRA and dacarbazine inhibits cell proliferation in the CD117 ${ }^{+}$melanoma cells. Results are as the mean \pm SD (standard deviation) of three independent experiments. 


\section{Statistical analysis}

The $I C_{50}$ values were calculated by Sigmaplot 12.0 software (Systat Software San Jose, CA). All data were analyzed using SPSS version 21 software (SPSS Inc., USA). The significant differences were determined using the student's t-test and one-way ANOVA followed by the Tukey post hoc comparison test $(P<0.05)$.
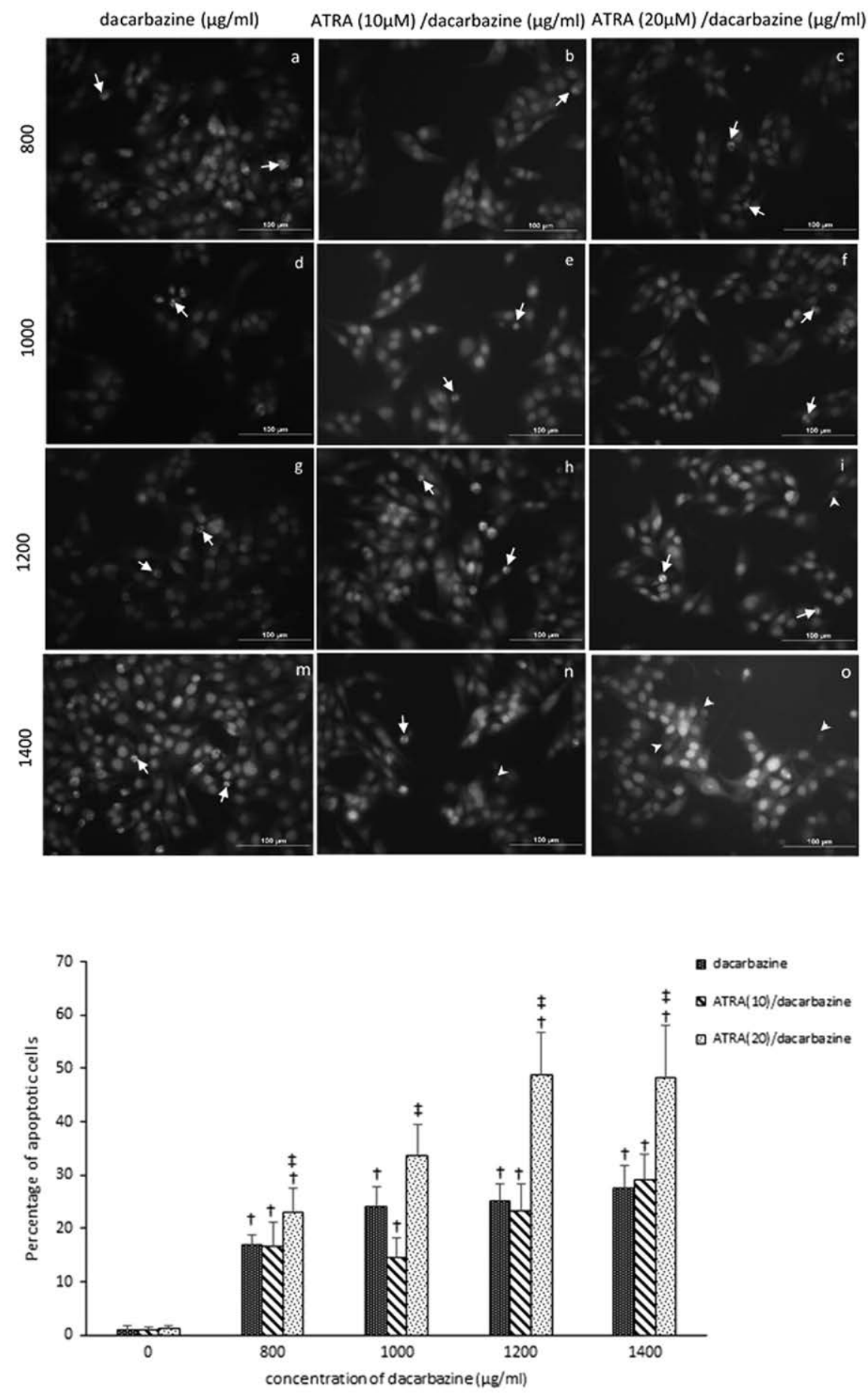

- Fig. 3 Morphological changes in nuclei of $\mathrm{CD} 117^{+}$melanoma cells following treatment with dacarbazine (a, d, g, and $\left.\mathbf{~ m}\right)$, ATRA ( $\left.10 \mu \mathrm{M}\right) /$ dacarbazine ( $\mathbf{b}, \mathbf{e}, \mathbf{h}$, and $\mathbf{n})$, and ATRA $(20 \mu \mathrm{M}) /$ dacarbazine $(\mathbf{c}, \mathbf{f}, \mathbf{i}$, and $\mathbf{o})$ evaluated by AO/EB staining. The arrows show apoptotic cells and the arrowheads show necrotic cells. The apoptotic cells significantly increased in a dose-dependent manner after treatment with dacarbazine and ATRA/dacarbazine (p). $† P<0.05$ compared to control group. $\ddagger P<0.05$ compared to dacarbazine alone. 


\section{Results}

\section{ATRA enhanced dacarbazine anticancer effect against $\mathrm{CD} 117^{+}$melanoma cell line}

We isolated $\mathrm{CD} 117^{+}$cells from the A375 melanoma cell line using MACS, which was confirmed by immunofluorescence microscopy ( Fig. 1). MTT assay was used to evaluate the cytotoxicity of ATRA, dacarbazine, and ATRA/dacarbazine. These drugs exerted a dosedependent manner against CD $117^{+}$melanoma cells following $48 \mathrm{~h}$ treatment. According to dose-response curves, dacarbazine had a weak growth-inhibitory effect on the $\mathrm{CD} 117^{+}$cells, while ATRA had a more cytotoxic effect. The $\mathrm{IC}_{50}$ values of dacarbazine and ATRA were $1583.09 \mu \mathrm{g} / \mathrm{ml}$ and $8.09 \mu \mathrm{M}$, respectively. Furthermore, $I_{50}$ values of combination treatment with low concentrations of ATRA (5 and $10 \mu \mathrm{M}$ ) and dacarbazine were not statistically significant compared to dacarbazine alone. Pretreatment with high-dose of ATRA $(20 \mu \mathrm{M})$ before dacarbazine was more effective than dacarbazine alone. The IC $C_{50}$ values of the combination of ATRA $(5 \mu \mathrm{M}$ and $10 \mu \mathrm{M})$ and dacarbazine were $1610.97 \pm 210.89$ and $1583.34 \pm 45.26 \mu \mathrm{g} / \mathrm{ml}$, respectively. The $\mathrm{IC}_{50}$ value of the combination of $20 \mu \mathrm{M}$ ATRA and dacarbazine $(914.21 \pm 51.3 \mu \mathrm{g} / \mathrm{ml}$.) was 1.7 fold less than dacarbazine alone ( $\triangleright$ Table 1 and $\triangleright$ Fig. 2 ).

\section{Morphological changes}

The morphological properties of the cells were determined by $\mathrm{AO} /$ EB staining ( $\triangleright$ Fig. 3 ). The results showed that combination treatment with ATRA and dacarbazine leads to a series of apoptotic morphological changes such as nuclear condensation, apoptotic bodies, and cell shrinkage, while viable cells exhibit green nuclei appearances in the control group. Dacarbazine treatment in all concentrations $(800,1000,1200,1400 \mu \mathrm{g} / \mathrm{ml})$ caused apoptosis in the $\mathrm{CD} 117^{+}$melanoma cells. Pretreatment with $10 \mu \mathrm{M}$ ATRA had not considerable changes in cell death compared to dacarbazine alone. In contrast, more apoptotic cells were seen after incubation of $\mathrm{CD} 117^{+}$melanoma cells with a combination of $20 \mu \mathrm{M}$ ATRA and dacarbazine.

\section{Effects of ATRA, dacarbazine and their combination treatment on the distribution of cell cycle}

In the next step, we used DAPi staining and flow cytometry to detect the effect of ATRA, dacarbazine, and their combination treatments on the cell cycle progression. The distribution of the cells within the cell cycle differs between ATRA-, dacarbazine-, and ATRA/dacarbazine- treated cells. The results showed that ATRA significantly increased the percentage of cells at the G0/G1 phase, while dacarbazine inhibited the cells at $\mathrm{S}$ phase. Furthermore, the distribution of the cell population significantly increased in the G0/ G1 phase following treatment with $20 \mu \mathrm{M}$ ATRA/dacarbazine ( $\triangleright$ Table 2 and $\triangleright$ Fig. 4 ).

\section{Discussion}

The main chemotherapies for melanoma are dacarbazine, temozolomide, and ipilimumab. Unfortunately, response rates are low and relapse occurs due to chemoresistance in melanoma. Although, there have been made many attempts to find novel medicine that might serve as more effective therapy to inhibit cancer growth, the efficacy is still unsatisfactory. ATRA exhibits anticancer activity through modulating melanoma cell growth and invasion [19]. It is commonly used to treat acute myeloid leukemia [20]. Xu et al. also revealed that ATRA inhibits the growth of squamous cell carcinoma cells by inducing the expression of RAR $\beta$ [21]. In fact, due to inducing differentiation of cancer stem cells, it is possible that ATRA used in combination with other chemotherapy agents to increase their efficacy. It has been reported that ATRA combinations with other drugs has cytotoxic effects on several cancer cell lines [22, 23]. In the previous study, we showed that ATRA was more effective to inhibit proliferation of $\mathrm{CD} 117^{+}$cells than $\mathrm{CD} 44^{+}$cells in the A375 melanoma cell line [18]. This study extended prior work by revealing the response of $\mathrm{CD} 117^{+}$cells to short-term ATRA pretreatment and dacarbazine. An interesting finding in our study was a significant decrease in $I C_{50}$ value following treatment with the combination of a high dose of ATRA and dacarbazine. We further demonstrated that a high dose of ATRA and dacarbazine strongly inhibited the $\mathrm{CD} 117^{+}$cells at the G0/G1 phase. Indeed, the combination treatment significantly increased apoptosis in the CD117 ${ }^{+}$ melanoma cells.

These data are consistent with those obtained from several studies. Recently, Li et al. encapsulated ATRA and dacarbazine in lipid nanoformulations. They showed that the simultaneous delivery of ATRA and dacarbazine resulted in significant inhibition of colony formation and cell proliferation in B16F10 melanoma cells. Similar to our study, they showed that the combination of ATRA and dacarbazine inhibited the melanoma cells at the sub-G0 phase [24].

In a study, Najafzadeh et al. planned a survey to determine the combination of ATRA as potent anticancer and chemotherapeutic drugs such as cisplatin and 5-fluorouracil to increase the efficacy of the drugs. They pretreated the cancer cells at low dose ATRA for 7 days [16], but in the present study, we pretreated the melanoma cells for a short time $(4 \mathrm{~h})$. Our results elucidated that a high dose of ATRA (for $4 \mathrm{~h}$ ) highly promotes the apoptotic effects of dacarbazine, which may be due to apoptosis and cell cycle arrest. Similarly, Zhang et al.

- Table 2 The $\mathrm{CD}_{117^{+}}$melanoma cells were treated with ATRA, dacarbazine, and ATRA/dacarbazine. Then, the cell cycle distribution was analyzed by flow cytometry.

\begin{tabular}{|l|l|l|l|}
\hline & G0/G1 \% & S\% & G2/M \% \\
\hline Control & $64.755 \pm 2.65$ & $3.54 \pm 0.63$ & $31.705 \pm 3.29$ \\
\hline ATRA & $82.28 \pm 5.6^{\mathrm{a}}$ & $2.6 \pm 2.6$ & $15.11 \pm 3.6$ \\
\hline dacarbazine & $69.41 \pm 4.12$ & $19.29 \pm 5.31^{\mathrm{a}}$ & $11.29 \pm 1.19$ \\
\hline ATRA/dacarbazine & $84.28 \pm 5.6^{\mathrm{ab}}$ & $3.31 \pm 0.95$ & $12.355 \pm 0.59$ \\
\hline aP<0.05 compared to control. b $P<0.05$ compared to dacarbazine alone. & \\
\hline
\end{tabular}



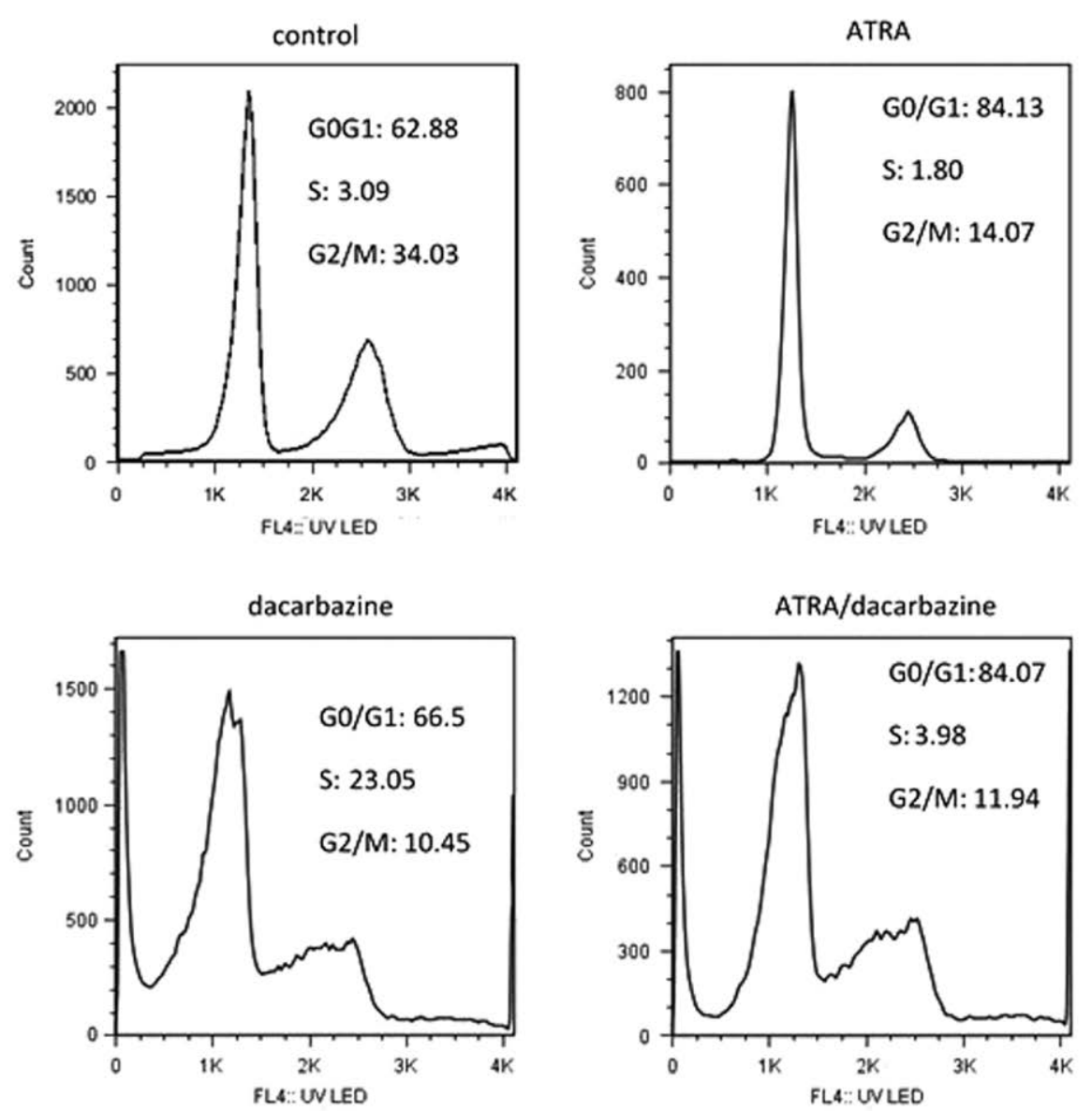

- Fig. 4 Effects of ATRA, dacarbazine, and ATRA/dacarbazine treatments on the cell cycle of $C D 117^{+}$melanoma cells. The percentage of cells in each phase of the cell cycle was obtained by flow cytometry analysis.

showed that at high concentrations ATRA causes cytotoxicity against melanoma cells after a long exposure time (3 days) [13]. In another study, Neumann et al. showed that long-term treatment with retinoid can upregulate CD117 expression and increases sensitivity for the imatinib mesylate in neuroblastoma [25]. Lindner et al. proved that the combination of retinoic acid and interferon-beta suppresses the growth of MCF-7 and NIH-OVCAR-3 tumors [26]. Also, in another similar study, Fang et al. (2010) demonstrated that ATRA stimulates cell cycle arrest at the G0/G10 phase through the upregulation of ubiquitin mRNA and increases 205 proteasome activity in the APL cells [27].

Indeed, several studies showed that ATRA alone or in combination with chemotherapeutics could not promote the cytotoxicity against some cancers. Demary et al. reported that the A375 melanoma cell line is resistant to ATRA, lowering intracellular ROS may increase the sensitivity of the cells to ATRA by enhancing RAR activity [28]. Retinoic acid receptors are not usually mutated in many cancers. Nevertheless, several mechanisms reported on the resistance to ATRA. Degradation of retinoids, downregulation of CRABP II, and efflux of retinoids from cells are possible mechanism affect the sensitivity of cancer cells to treatment with retinoids [29].
We conclude that the combination treatment of short-term low dose ATRA did not significantly enhance the cytotoxic effects of dacarbazine on melanoma $\mathrm{CD} 117^{+}$cells. Furthermore, the combination of ATRA and dacarbazine can inhibit the cell cycle progression at the G0/G1 phase.

\section{Acknowledgement}

The authors gratefully acknowledge use of the services and facilities of the Ardabil University of Medical Sciences.

\section{Funding}

This work was supported by a thesis grant for MD from Ardabil University of Medical Sciences (Grant No. 0694).

\section{Ethical Approval}

This article does not contain any studies with human participants or animals performed by any of the authors. 


\section{Conflict of Interest}

All authors declare that they have no conflict of interest. The authors declare that the research was conducted in the absence of any commercial or financial relationships that could be construed as a potential conflict of interest.

\section{References}

[1] Leonardi GC, Falzone L, Salemi R et al. Cutaneous melanoma: From pathogenesis to therapy. International Journal of Oncology 2018; 52: 1071-1080

[2] Jemal A, Ward EM, Johnson C] et al. Annual report to the nation on the status of cancer, 1975-2014, featuring survival. JNCl: Journal of the National Cancer Institute 2017; 109: djx030

[3] Matthews NH, Li W-Q, Qureshi AA et al. Epidemiology of melanoma. In: Cutaneous Melanoma: Etiology and Therapy [Internet]. Codon Publications, 2017

[4] Soengas MS, Lowe SW. Apoptosis and melanoma chemoresistance. Oncogene 2003; 22: 3138-3151

[5] Serrone L, Zeuli M, Sega F et al. Dacarbazine-based chemotherapy for metastatic melanoma: thirty-year experience overview. Journal of Experimental \& Clinical Cancer Research: CR 2000; 19: 21-34

[6] Khayat D, Bernard-Marty C, Meric J-B et al. Biochemotherapy for advanced melanoma: Maybe it is real. American Society of Clinical Oncology. 2002

[7] Bajetta E, Del Vecchio M, Bernard-Marty C et al. Metastatic melanoma: Chemotherapy. In: Seminars in Oncology 2002; 5: Elsevier 427-445

[8] Longley B], Reguera M], Ma Y. Classes of c-KIT activating mutations: proposed mechanisms of action and implications for disease classification and therapy. Leukemia Research 2001; 25: 571-576

[9] Leong KG, Wang B-E, Johnson L et al. Generation of a prostate from a single adult stem cell. Nature 2008; 456: 804-808

[10] Linnekin D. Early signaling pathways activated by c-Kit in hematopoietic cells. The International Journal of Biochemistry \& Cell Biology 1999; 31: 1053-1074

[11] Foster BM, Zaidi D, Young TR et al. CD117/c-kit in cancer stem cell-mediated progression and therapeutic resistance. Biomedicines 2018; 6: 31

[12] Garcia JJ, Kramer M], Mackey ZB et al. Utility of CD117 immunoreactivity in differentiating metastatic melanoma from clear cell sarcoma. Archives of Pathology \& Laboratory Medicine 2006; 130: 343-348

[13] Zhang H, Satyamoorthy K, Herlyn M et al. All-trans retinoic acid (atRA) differentially induces apoptosis in matched primary and metastatic melanoma cells-a speculation on damage effect of atRA via mitochondrial dysfunction and cell cycle redistribution. Carcinogenesis 2003; 24: 185-191

[14] Yin W, Song Y, Liu Q et al. Topical treatment of all-trans retinoic acid inhibits murine melanoma partly by promoting CD8(+) T-cell immunity. Immunology 2017; 152: 287-297
[15] Eggermont AM, Kirkwood JM. Re-evaluating the role of dacarbazine in metastatic melanoma: what have we learned in 30 years? European Journal of Cancer 2004; 40: 1825-1836

[16] Najafzadeh N, Mazani M, Abbasi A et al. Low-dose all-trans retinoic acid enhances cytotoxicity of cisplatin and 5-fluorouracil on CD44(+) cancer stem cells. Biomedicine \& Pharmacotherapy 2015; 74: 243-251

[17] Aebi S, Kröning R, Cenni B et al. All-trans retinoic acid enhances cisplatin-induced apoptosis in human ovarian adenocarcinoma and in squamous head and neck cancer cells. Clinical Cancer Research 1997; 3: 2033-2038

[18] Mohammadi Jobani B, Najafzadeh N, Mazani M et al. Molecular mechanism and cytotoxicity of allicin and all-trans retinoic acid against CD44 + versus CD117 + melanoma cells. Phytomedicine : International Journal of Phytotherapy and Phytopharmacology 2018; 161-169

[19] Wood W, Seftor E, Lotan D et al. Retinoic acid inhibits human melanoma tumor cell invasion. Anticancer Research 1990; 10: 423-432

[20] Küley-Bagheri Y, Kreuzer KA, Monsef I et al. Effects of all trans retinoic acid (ATRA) in addition to chemotherapy for adults with acute myeloid leukaemia (AML)(non acute promyelocytic leukaemia (non APL)). Cochrane Database of Systematic Reviews (8) 2018; 8: CD011960

[21] Xu X-C, Liu X, Tahara E et al. Expression and up-regulation of retinoic acid receptor- $\beta$ is associated with retinoid sensitivity and colony formation in esophageal cancer cell lines. Cancer Research 1999; 59: 2477-2483

[22] Freemantle S], Spinella M], Dmitrovsky E. Retinoids in cancer therapy and chemoprevention: promise meets resistance. Oncogene 2003; 22: 7305-7315

[23] Adamson PC. All-Trans-Retinoic Acid Pharmacology and Its Impact on the Treatment of Acute Promyelocytic Leukemia. The Oncologist 1996; 1: 305-314

[24] Li C, Han X. Co-delivery of Dacarbazine and All-Trans Retinoic Acid (ATRA) Using Lipid Nanoformulations for Synergistic Antitumor Efficacy Against Malignant Melanoma. Nanoscale Research Letters 2020; 15: $1-10$

[25] Neumann I, Foell JL, Bremer M et al. Retinoic acid enhances sensitivity of neuroblastoma cells for imatinib mesylate. Pediatric Blood \& Cancer 2010; 55: 464-470

[26] Lindner D], Borden EC, Kalvakolanu DV. Synergistic antitumor effects of a combination of interferons and retinoic acid on human tumor cells in vitro and in vivo. Clinical Cancer Research 1997; 3: 931-937

[27] Fang Y, Zhou X, Lin M et al. The ubiquitin-proteasome pathway plays essential roles in ATRA-induced leukemia cells G0/G1 phase arrest and transition into granulocytic differentiation. Cancer Biology \& Therapy 2010; 10: 1157-1167

[28] Demary K, Wong L, Liou JS et al. Redox control of retinoic acid receptor activity: a novel mechanism for retinoic acid resistance in melanoma cells. Endocrinology 2001; 142: 2600-2605

[29] Chlapek P, Slavikova V, Mazanek P et al. Why differentiation therapy sometimes fails: molecular mechanisms of resistance to retinoids. International Journal of Molecular Sciences 2018; 19: 132 